\title{
An Accurate Iron Core Loss Model in Equivalent Circuit of Induction Machines
}

\author{
Bilal Abdullah Nasir (i) \\ Northern Technical University, Hawijah Technical Institute, Iraq \\ Correspondence should be addressed to Bilal Abdullah Nasir; bilal_alnasir1958@yahoo.co.uk
}

Received 15 November 2019; Accepted 16 January 2020; Published 15 February 2020

Academic Editor: Johan E. Hustad

Copyright (C) 2020 Bilal Abdullah Nasir. This is an open access article distributed under the Creative Commons Attribution License, which permits unrestricted use, distribution, and reproduction in any medium, provided the original work is properly cited.

\begin{abstract}
Iron core loss is the major loss in electrical machines. It performs up to $25 \%$ of total machine losses. The machine efficiency calculation requires an accurate prediction of losses. The accuracy of losses calculation depends largely on the equivalent circuit parameter determination and measurements. In this paper, an accurate procedure of iron core loss determination considering the variation effect of supply voltage, iron core temperature, rotor parameters due to skin effect, and magnetizing saturation. The iron core resistance is performed as main component in the equivalent circuit. This resistance is a function of supply voltage and used to calculate part of stray loss as well as iron core loss. The theoretical model is compared with practical results with high accuracy, which proves the validity of the proposed procedure.
\end{abstract}

\section{Introduction}

Iron core losses in electrical induction machines operate with sinusoidal power supplies account for $15-25 \%$ of the total machine losses $[1,2]$, which are one of the major losses in electrical machines. The accurate prediction of iron core losses and then machine efficiency requires accurate quantification of core losses during the machine design process, essentially for electromagnetic and thermal design of electrical machines.

The losses in the stator and rotor iron cores are due to the space fundamental and harmonic fluxes. These losses consist of hysteresis loss, eddy current loss, and excess loss. Hysteresis and eddy current losses are proportional to frequency and square of frequency, respectively.

Time-varying rotating magnetic flux inside the machine causes the magnetic material to experience a cyclic variation, resulting in hysteresis loss, which depends on the area of the loop and frequency. Under normal operation of the machine, the rotor current frequency is very small, and hence, the hysteresis loss in the rotor core can be neglected, while the stator current frequency is the same as that of the supply and hysteresis loss in the stator core is appreciable.

The second part of core losses is the eddy current loss. Eddy currents are circulating in the laminations of the iron core due to the e.m.f. induced in the laminations when they are subjected to alternating fluxes. The direction of eddy currents in the iron core is so to oppose the change in the flux and force the magnetic field to the outer surfaces due to the magnetic skin effect. This process produces heat in the iron cores and, hence, eddy current losses.

The third core loss, which is called "excess loss" is proportional to three-halves power of frequency and magnetic flux density subjected to the iron cores. This excess loss is due to the nonuniform distribution of magnetic flux density in the laminations and created by both nonlinear diffusions of magnetic flux density and skin effect. Classical eddy current loss is calculated based on the assumption of the uniform field distribution, which is only valid for materials working at large skin depth. Skin depth decreases as frequency increases, and the excess loss occupies a lower 


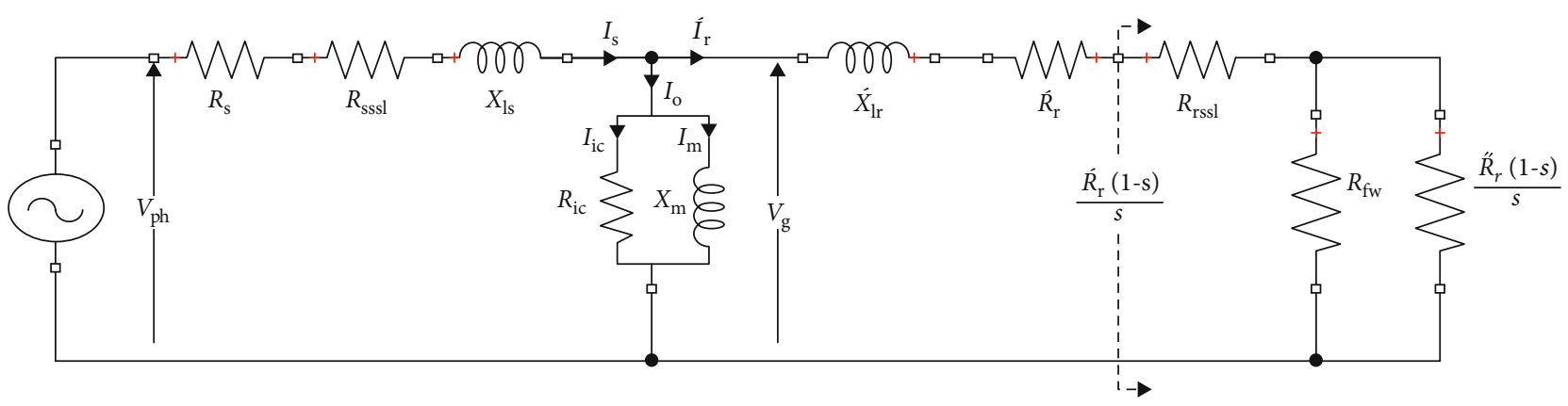

FIgUre 1: Proposed steady-state equivalent circuit of induction motor per phase.

portion of the total losses at high frequencies when the skin depth is small [3]. Many different iron core loss models have been developed.

Levi [4] has derived mathematical models of current vector-controlled induction machines that account for iron core loss calculations (present the equivalent machine circuit). The models show that decoupled flux and torque control cannot take place when the iron core losses are neglected, and the amount of detuning is presented in a steady-state operation of the machine. Hence, the impact of iron core losses cannot be neglected. Ionel et al. [5] have proposed a model for iron core loss calculations in electrical machines. In this model, the hysteresis loss is variable with frequency and magnetic flux density, while eddy current and excess losses are variable with magnetic flux density only. The influence of skin effect, core temperature, slip, and magnetic saturation is not considered. Popescu and Ionel [6] have proposed a model for power loss calculation in the iron laminated steel core, taking the variation of frequency and magnetic flux density into consideration. His model can be applicable to iron core loss calculations of induction machines, but the effect of skin, temperature variation, slip, and magnetic saturation is not considered. Laldin [7] has proposed a model for iron core loss calculation with maintaining somewhat simple algorithm and good accuracy, but the model neglected the temperature dependency of the iron core, the rotor core loss, the slip, the skin effect, the magnetic saturation, and the excess iron core loss. Manyage [8] has proposed an improved iron core loss model with introducing the skin effect in the eddy current loss calculation. In this model, the influence of iron core temperature, slip, and magnetic saturation is not considered. Akiror [9] has proposed a model for iron core loss calculations, but the model neglects the temperature effect on the core losses, the rotor iron core losses, the effect of skin, the effect of slip, and the magnetic saturation.

In this paper, a new model for iron core loss calculation of induction machines was proposed. Both stator and rotor iron core loss calculations are taken into account separately by the calculation of their core resistances. The two core resistances can be connected in parallel with the magnetizing reactance, and then, they can be replaced by an equivalent iron core resistance to determine the iron core losses accurately. In the proposed model, the excess iron core loss, the influence of variations of supply voltage (magnetic flux density) and frequency, the skin effect, the core losses, and the magnetic saturation effect on the magnetizing inductance are considered in the iron core loss determinations.

\section{Estimation of Iron Core Losses}

Naturally, it is considered that iron core losses taking 1-4\% of the induction machine rated power and the stray load loss taking about $0.5-3 \%$ of rated machine power. Elimination of these losses from the equivalent circuit parameter calculation leads to a significant impact on the machine efficiency calculation. In addition to reducing efficiency, iron core losses generally increase the temperature within the machine and reducing its loading capacity. Therefore, these losses are far from negligible, and it can be suspected that they are higher in small machines (up to $15 \mathrm{KW}$ rated power), which are observed to have reduced efficiency when compared to large machines (more than $15 \mathrm{KW}$ rated power). Under noload conditions, the iron core losses are usually determined by subtracting the mechanical (friction and windage) and stator copper losses from the measured no-load input power of the machine, according to the widely used international standards IEEE $112-\mathrm{B}$ and IEC $60034-2-1$ as $[10,11]$

$$
P_{\text {ic }}=P_{\text {in }}-P_{\text {scu }}-P_{\mathrm{f} \omega}
$$

where $P_{\text {ic }}$ is the iron core losses, $P_{\text {in }}$ is the no-load input power, and $P_{\text {scu }}$ is the stator copper loss.

$P_{\mathrm{f} \omega}$ is the friction and windage losses, which can be separated from the no-load input power by rotating the machine at a synchronous speed using D.C or a synchronous motor.

Core losses are usually modeled by a resistor $R_{\mathrm{ic}}$ connected in parallel with the magnetizing reactance $X_{\mathrm{m}}$ as shown in the proposed machine equivalent circuit of Figure 1.

$R_{s}$ and $\dot{R}_{r}$ are the stator and rotor phase resistances referred to stator side, respectively.

$X_{\ell s}$ and $\dot{X}_{\ell r}$ are the stator and rotor leakage reactances referred to stator side, respectively. $V_{\mathrm{ph}}$ is the motor supply phase voltage. $R_{\mathrm{sssl}}$ and $R_{\mathrm{rssl}}$ are the stator and rotor stray load loss resistances, respectively. 
$I_{s}$ and $\dot{I}_{r}$ are the stator rotor phase currents referred to stator side. $S$ is the motor slip. $I_{\mathrm{ic}}$ is the per phase iron core current, $I_{m}$ is the magnetizing current, and $I_{o}$ is the no-load current. $V_{g}$ is the air-gap or magnetizing voltage per phase and can be calculated as [10]

$$
V_{g}=\sqrt{\left(V_{\mathrm{ph}}-\left(\frac{\mathrm{R}_{s} \cdot P_{\mathrm{in}}+X_{\mathrm{ls}} \cdot Q_{\mathrm{in}}}{V_{\mathrm{ph}}}\right)\right)^{2}+\left(\frac{X_{\mathrm{ls}} \cdot P_{\mathrm{in}}-R_{s} \cdot Q_{\mathrm{in}}}{V_{\mathrm{ph}}}\right)^{2}},
$$

where $Q_{\text {in }}$ and $P_{\text {in }}$ are the no-load measured active and reactive powers per phase.

Then, the iron core resistance can be calculated from equations (1) and (2) as

$$
R_{\mathrm{ic}}=\frac{V_{g}^{2}}{P_{\mathrm{ic}}} .
$$

At load, the iron core losses can be calculated as

$$
P_{\mathrm{ic}}=P_{\mathrm{in}}-P_{\mathrm{sscu}}-P_{\mathrm{rscu}}-P_{\mathrm{f} \omega}
$$

where $P_{\text {sscu }}$ is the stator copper and stray load loss power and can be calculated as

$$
P_{\mathrm{sscu}}=3 * I_{s} *\left(R_{s}+R_{\mathrm{sss}}\right),
$$

where $P_{\text {rscu }}$ is the rotor copper loss and can be calculated as

$$
P_{\text {rscu }}=3 *\left(I_{s}-I_{o}\right)^{2} *\left(\dot{R}_{r}+\mathrm{R}_{\mathrm{rssl}}\right) .
$$

The international standards do not deal with the variation of the supply voltage (magnetic flux density) and supply frequency $\left(f_{s}\right)$ and their influencing on iron losses. Furthermore, the rotor iron core losses are commonly neglected due to the low rated slip of the machine.

Other approaches to assess the iron core losses include measurements on magnetic materials $[12,13]$, thermometric methods [14], and finite element analysis [5, 15], but they involve extensive experimental testing or intensive computational time or lack of generality.

In my opinion, the previous studies have failed to provide an accurate expression for the iron core loss calculations to apply for the induction machine at various operating conditions (variable voltage-variable frequency). Therefore, the aim of this study is to fill the methodological gap and provide an expression for iron core loss calculation including stator and rotor iron core losses of the induction machine taking into account the variation in operating condition, such as supply voltage, supply frequency, skin effect, saturation in magnetizing reactance, machine slip, and iron core loss temperature dependency.

\section{The Proposed Iron Core Loss Model}

The iron core loss in induction machines is commonly divided into three principal contributors, namely, hysteresis loss, eddy current loss, and excess or anomalous loss. These loss components are separated from each other in order to achieve a better agreement between measured and predicted results, as in Bertotti's model [16]. In order to preserve the simplicity, the Basic model [17] takes the iron core loss coefficient (hysteresis and eddy current) variation with supply voltage (magnetic flux) and constant supply frequency and omitting the excess loss coefficient. Also, in [17], the rotor iron loss, the temperature dependence of machine iron loss, the machine slip, the skin effect, and the saturation are neglected and the loss coefficients are calculated by the trial-and-error method.

To calculate the iron core power losses accurately in induction machines, the model must include calculations of stator and rotor core losses separately and then added together to perform the total iron core losses. The variation in supply voltage and frequency must be considered by calculating the hysteresis, eddy current, and excess loss coefficients as a function of supply voltage and frequency. The machine slip influence on the rotor iron core due to the variation in rotor current frequency must be considered in the model. The skin effect on the core losses can be considered, but this influence appears only at high supply frequency (more than $500 \mathrm{~Hz}$ ) and can be considered for high-speed induction motors fed from inverters. Temperature influences on the iron core losses of stator and rotor must be considered. The effect of magnetizing saturation on the magnetizing or air-gap voltage must be considered, due to a reduction in air-gap voltage which leads to a reduction in the iron core losses. The equations of the whole iron power losses in the stator and rotor of an induction machine can be stated as follows.

\subsection{For Stator Iron Core Power Loss.}

$$
P_{\text {sic }}=K_{h} \cdot f_{s} \cdot B_{m}^{T}+K_{e} \cdot f_{s}^{2} \cdot B_{m}^{2}+K_{\text {ex }} \cdot f_{s}^{1.5} \cdot B_{m}^{1.5},
$$

where $K_{h}, K_{e}$, and $K_{\mathrm{ex}}$ are the hysteresis, eddy current, and excess iron core loss coefficients for stator and rotor cores, respectively, and can be determined from the experimental test. $f_{s}$ is the supply frequency. $\Gamma$ is the Steinmetz coefficient, which can be calculated from the test, or it can be assumed equal to 2.0 in case of sinusoidal supply voltage and steel lamination core.

$B_{m}$ is the amplitude air-gap flux density and can be transformed in terms of air-gap or magnetizing voltage per phase $\left(V_{g}\right)$ as

$$
B_{m}=\frac{V_{g}}{\left(K \cdot \omega_{s}\right)},
$$

where $\omega_{s}$ is the stator angular frequency $\left(2 \pi f_{s}\right)$ and $K$ is a constant which can be given from the induction machine theory [1] as

$$
K=N_{\mathrm{ph}} \cdot K_{\omega} \cdot \frac{A}{P},
$$


where $N_{\mathrm{ph}}$ is the stator turns per phase, $K_{\omega}$ is the winding factor, and $A$ is the air-gap area and can be calculated as

$$
A=S_{b} * \ell_{\text {stack }}
$$

where $S_{b}$ is the stator bore diameter and $\ell_{\text {stack }}$ is the stator stack length.

$P$ is the machine magnetic pole pairs.

Therefore, substituting equation (8) into (7) to obtain

$$
P_{\mathrm{sic}}=\dot{K}_{h} \cdot f_{s} \cdot\left(\frac{V_{g}}{\omega_{s}}\right)^{\Gamma}+\dot{K}_{e} \cdot f_{s}^{2} \cdot\left(\frac{V_{g}}{\omega_{s}}\right)^{2}+\dot{K}_{\mathrm{ex}} \cdot f_{s}^{1.5} \cdot\left(\frac{V_{g}}{\omega_{s}}\right)^{1.5} \text {, }
$$

where $\dot{K}_{h}, \dot{K}_{e}$, and $\dot{K}_{\text {ex }}$ are the new coefficients of iron core losses.

Equation (11) can be rearranged as

$$
P_{\text {sic }}=\left[\frac{\dot{K}_{h}}{\omega_{s}} \cdot\left(\frac{V_{g}}{\omega_{s}}\right)^{\Gamma-2}+\stackrel{\prime}{K}_{e}+\frac{\dot{K}_{\mathrm{ex}}}{\sqrt{V_{g}}}\right] \cdot V_{g}^{2},
$$

where $\dot{K}_{h}, \dot{K}_{e}$, and $\dot{K}_{\text {ex }}$ are the new coefficients of iron core losses.

The stator core resistance $\left(R_{\mathrm{sic}}\right)$ can be calculated from equation (12) as

$$
R_{\mathrm{sic}}=\frac{1}{\left[\left(\dot{K}_{h}^{\prime} / \omega_{s}\right) \cdot\left(V_{g} / \omega_{s}\right)^{\Gamma-2}+\dot{K}_{e}+\left(\dot{K}_{\mathrm{ex}} / \sqrt{V_{g}}\right)\right]} .
$$

For a sinusoidal supply voltage of induction motor, the coefficient $(\Gamma)$ can be replaced by 2.0 to obtain

$$
R_{\mathrm{sic}}=\frac{1}{\left[\left(\dot{K}_{h} / \omega_{s}\right)+\dot{K}_{e}+\left(\dot{K}_{\mathrm{ex}} / \sqrt{V_{g}}\right)\right]} .
$$

From equation (14), it can be noticed that the iron core power loss depends on the supply voltage and frequency.

3.2. For Rotor Iron Core Power Loss. Similarly, with the same procedure of determining stator iron core power and iron core resistance, the rotor core loss and rotor core resistance can be derived in terms of rotor frequency $\left(f_{r}=s f_{s}\right)$ and air-gap voltage $\left(V_{g}\right)$. In a similar manner, the rotor iron core power loss $P_{\text {ric }}$ can be obtained as

$$
P_{\text {ric }}=S^{2} *\left[\frac{\dot{K}_{h}}{\omega_{s l}}+\dot{K}_{e}+\frac{\dot{K}_{\mathrm{ex}}}{\sqrt{s V_{g}}}\right] * V_{g}^{2} .
$$

The rotor core resistance can be determined as

$$
R_{\mathrm{ric}}=\frac{1}{\left[S^{2} *\left[\left(\dot{K}_{\mathrm{h}} / \omega_{\mathrm{se}}\right)+\dot{\prime}_{e}+\left(\dot{\prime}_{\mathrm{ex}} / \sqrt{s \cdot V_{\mathrm{g}}}\right)\right]\right]}
$$

or

$$
R_{\text {ric }}=\frac{R_{\text {sic }}}{S^{2}}
$$

The equivalent iron core resistance $R_{\mathrm{ic}}$ can be calculated as

$$
R_{\mathrm{ic}}=R_{\mathrm{sic}} \| R_{\mathrm{ric}}=\frac{R_{\mathrm{sic}}}{\left(1+S^{2}\right)}
$$

The iron core losses depended on supply voltage, supply frequency, and motor slip.

\section{Skin Effect Dependent on Iron Core Loss Model}

If the skin effect is considered in the core power loss model, the modified iron core loss of stator, equation (7), becomes

$$
P_{\mathrm{sic}}=K_{h} \cdot f_{s} \cdot B_{m}^{\Gamma}+K_{\mathrm{sk}} \cdot K_{e} \cdot f_{s}^{2} \cdot B_{m}^{2}+K_{\mathrm{ex}} \cdot f_{s}^{1.5} \cdot B_{m}^{1.5} .
$$

The skin effect is comprised in the $K_{\text {sk }}$ factor, which is a function of skin depth $(\delta)$ and lamination thickness $(d)$.

The skin effect factor $\left(K_{s k}\right)$ can be given as [18]

$$
K_{\mathrm{sk}}=\frac{3}{\lambda} \cdot \frac{[\sinh (\lambda)-\sin (\lambda)]}{[\cosh (\lambda)-\cos (\lambda)]},
$$

where

$$
\begin{aligned}
& \lambda=\frac{d}{\delta}, \\
& \delta=\frac{1}{\sqrt{\pi \cdot f \cdot \mathfrak{S} \cdot \mu}},
\end{aligned}
$$

where $f=f_{\mathrm{s}}$ in the stator iron core. $f=s \cdot f_{\mathrm{s}}$ in the rotor iron core. $\mathbb{S}$ is the electrical conductivity of iron material $(\mathrm{S} / \mathrm{m}) . \mu$ is the magnetic permeability of iron core material $(\mathrm{H} / \mathrm{m}) . f$ is the frequency of the core magnetic flux $(\mathrm{Hz})$.

The skin-effect factor $K_{\text {sk }}$ is used in the eddy current term of equation (19) to consider the impact of higher frequencies (more than $500 \mathrm{~Hz}$ ) on the iron core loss determination. For low frequencies (less than $500 \mathrm{~Hz}$ ), which is the case used in this study, this effect, as well as edge effect, has been studied by means of one-, two-, and three-dimensional finite element analysis in lamination models and has been found to be unimportant and can be neglected.

\section{Temperature-Dependent Iron Core Loss Model}

Eddy current loss in the iron core is the main responsible for the decrease of iron core loss with increasing temperature. This explains the phenomenon that in the higher frequency, the iron loss decreases when the temperature rises, since static hysteresis loss is proportional to frequency while eddy current loss is proportional to the square of the frequency. Therefore, with increasing frequency, eddy current loss 
component takes more share of total iron core loss. Eddy current loss component decreases with temperature rising due to an increase in lamination resistance and reduction in magnetic flux density. But static hysteresis loss component almost remains constant when the temperature rises. Based on the above fact, the proposed iron core loss model of equation (19) can be modified or expressed as [19]

$$
P_{\mathrm{sic}}=K_{h} \cdot f_{s} \cdot B_{m}^{\Gamma}+\frac{K_{\mathrm{sk}} \cdot K_{e} \cdot f_{s}^{2} \cdot B_{m}^{2}}{\left[1+\propto_{\mathrm{ic}}\left(T_{f}-T_{o}\right)\right]}+K_{\mathrm{ex}} \cdot f_{s}^{1.5} \cdot B_{m}^{1.5},
$$

where $T_{o}$ is the base or ambient iron core temperature $\left({ }^{\circ} \mathrm{C}\right)$. $T_{\mathrm{f}}$ is the final iron core temperature $\left({ }^{\circ} \mathrm{C}\right)$.

$\propto_{i c}$ is the temperature coefficient of iron material. It is introduced for equivalent resistivity in the iron core loss model to consider a thermal effect on eddy current loss in the iron core. The equivalent resistivity of the iron core increases linearly with temperature if $\propto_{i c}$ takes a positive value as [19]

$$
\begin{aligned}
\rho_{(T)} & =\rho_{o} *\left[1+\propto_{\mathrm{ic}} \cdot\left(T_{f}-T_{o}\right)\right], \\
K_{e} & =\frac{\pi^{2} * d^{2}}{6 * \rho_{(T)}},
\end{aligned}
$$

where $\rho_{\mathrm{o}}$ is the base value of iron core resistivity.

$\rho_{(T)}$ is the iron core resistivity at any temperature, and $d$ is the lamination thickness.

An improved model of iron core loss takes the temperature effect on both eddy current loss and hysteresis loss as well as excess iron loss can be expressed to achieve good accuracy and easily implemented as [20]

$$
P_{\operatorname{sic}(T)}=K_{T} * P_{\operatorname{sic}\left(T_{o}\right)},
$$

where $P_{\operatorname{sic}(T)}$ is the stator iron core power loss at any actual temperature $(T) . P_{\operatorname{sic}\left(T_{o}\right)}$ is the stator base iron power loss, which is given by equation (22).

$K_{T}$ is the temperature coefficient, which is representing the ratio of iron core losses at temperature $(T)$ and at temperature $\left(T_{o}\right)$, and can be expressed as

$$
\begin{aligned}
K_{T} & =(1-D), \\
D & =\frac{\left(P_{\operatorname{sic}\left(T_{o}\right)}-P_{\operatorname{sic}(T)}\right)}{P_{\operatorname{sic}\left(T_{o}\right)}},
\end{aligned}
$$

where $D$ is the iron core power loss varying rate per ${ }^{\circ} \mathrm{C}$. A positive value of $D$ means that the iron core loss decreases with temperature rise, while a negative value of $D$ indicates that the iron loss increases with temperature rise. The value of $D$ can be determined from the measured iron core loss at two different temperatures at fixed frequency and supply voltage.

Based on the improved model of iron core losses, both hysteresis and eddy current loss coefficients vary approxi- mately linearly with temperature. These linear variations have also been confirmed in $[21,22]$. Nevertheless, the relationship between these losses and temperature will be far away from linear when the temperature is above $200^{\circ} \mathrm{C}$ [23].

However, electrical machines rarely operate at a temperature higher than $200^{\circ} \mathrm{C}$. A simple linear relationship between the coefficients and the temperature can be considered for the typical operating temperature range of electrical machines. Also, the varying rates of hysteresis and eddy current core loss coefficients with temperature are different even under the same frequency and supply voltage. If all these aspects are considered, the temperature-dependent iron core loss coefficients can be modeled as [23]

$$
\begin{aligned}
P_{\mathrm{sic}}= & K_{T h} \cdot K_{h T_{o}} \cdot f_{s} \cdot B_{m}^{\Gamma}+K_{T e} \cdot K_{e T_{o}} \cdot K_{\mathrm{sk}} \cdot f_{s}^{2} \cdot B_{m}^{2} \\
& +K_{T \mathrm{ex}} \cdot K_{\mathrm{ex} T_{o}} \cdot f_{s}^{1.5} \cdot B_{m}^{1.5},
\end{aligned}
$$

where $K_{T h}, K_{T e}$, and $K_{T e x}$ are temperature-dependent coefficients of hysteresis, eddy current, and excess core losses. $K_{h T_{o}}, K_{e T_{o}}$, and $K_{e x T_{o}}$ are the hysteresis, eddy current, and excess core loss coefficients at the temperature $T_{o}$.

The temperature-dependent coefficients can be expressed as

$$
\begin{gathered}
K_{T h(T)}=1+D_{h}, \\
K_{T e(T)}=1+D_{e}, \\
K_{T \operatorname{ex}(T)}=1+D_{\mathrm{ex}},
\end{gathered}
$$

where $D_{h}, D_{e}$, and $D_{\text {ex }}$ are the varying rates of hysteresis, eddy current, and excess iron core loss coefficients with temperature and can be determined by measured iron core loss at different low temperatures $T_{o}$ and $T_{1}$ for the same frequency and supply voltage as [23]

$$
\begin{gathered}
D_{h}=\frac{K_{h\left(T_{1}\right)}-K_{h\left(T_{o}\right)},}{K_{h\left(T_{o}\right)}}, \\
D_{e}=\frac{K_{e\left(T_{1}\right)}-K_{e\left(T_{o}\right)}}{K_{e\left(T_{o}\right)}}, \\
D_{e x}=\frac{K_{\operatorname{ex}\left(T_{1}\right)}-K_{\operatorname{ex}\left(T_{o}\right)}}{K_{\operatorname{ex}\left(T_{o}\right)}},
\end{gathered}
$$

where $K_{h\left(T_{1}\right)}, K_{h\left(T_{o}\right)}, K_{e\left(T_{1}\right)}, K_{e\left(T_{o}\right)}, K_{\mathrm{ex}\left(T_{1}\right)}$, and $K_{\mathrm{ex}\left(T_{o}\right)}$ are the hysteresis, eddy current, and excess core loss coefficients at the temperature $T_{1}$ and $T_{o}$, respectively. Temperature $T_{o}$ can be set to $25^{\circ} \mathrm{C}$ and temperature $T_{1}$ can be set to $70^{\circ} \mathrm{C}$.

Positive $D_{h}, D_{e}$, and $D_{\text {ex }}$ means that the iron core losses increase with temperature rise, while negative values of these varying rate coefficients mean that iron core losses decrease with temperature rise.

The advantages of this temperature-dependent model of that the hysteresis, eddy current, and excess losses can be considered separately, and the temperature influence on iron core losses can be considered by measuring results at only 


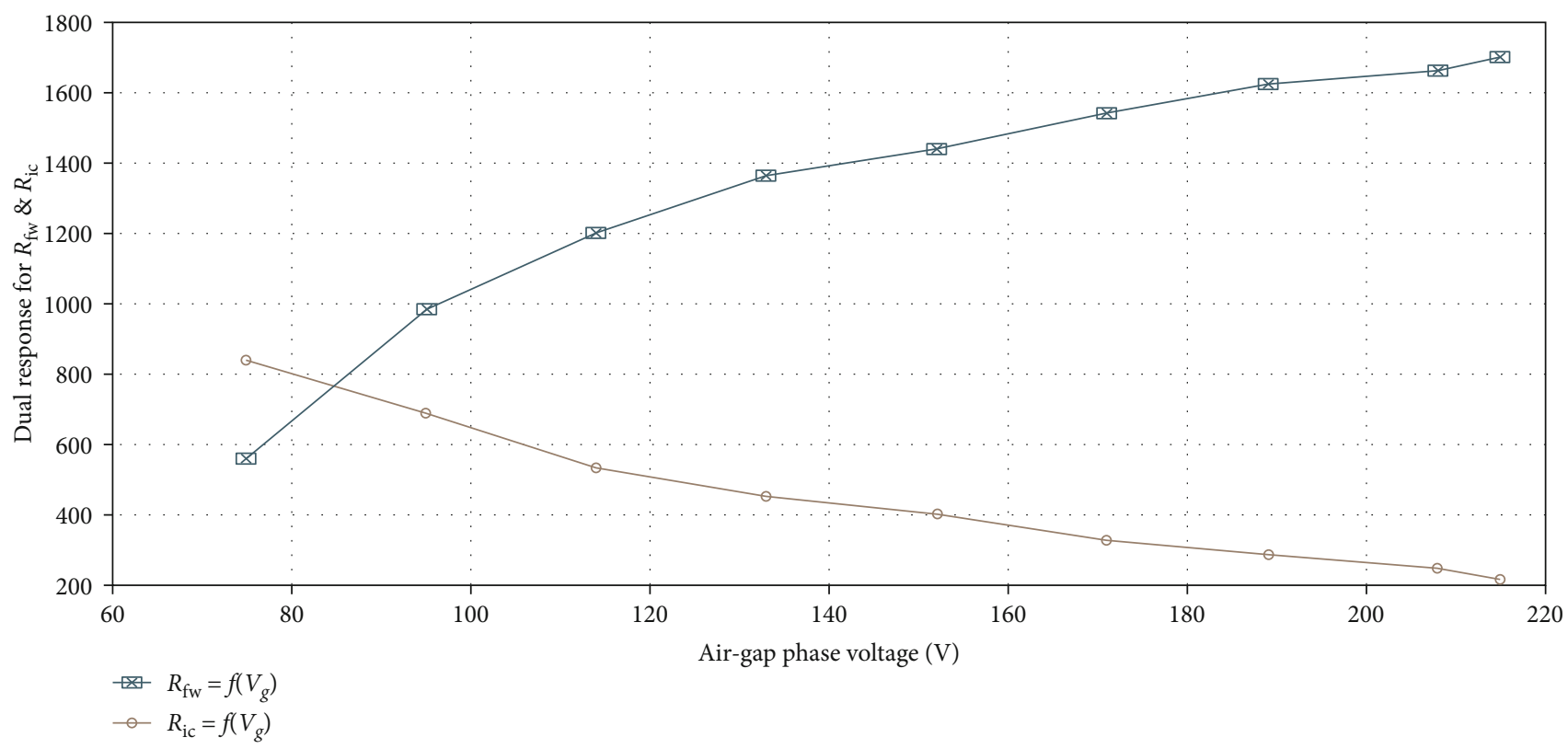

FIGURE 2: Variation of iron core and mechanical loss resistances with air-gap voltage.

two different temperature points. Then, from equations (18) and (24), the equivalent iron core resistance, taking the effect of machine slip and iron core temperature into account, can be calculated as

$$
R_{\mathrm{ic}(T)}=\frac{R_{\mathrm{sic}(T)}}{\left(1+S^{2}\right)}=\frac{V_{g}^{2}}{P_{\mathrm{ic}(T)}},
$$

where the air-gap voltage $\left(V_{g}\right)$ can be calculated from equation (2) or can be calculated in terms of magnetizing reactance $\left(X_{m}\right)$ and magnetizing current $\left(I_{m}\right)$ as

$$
V_{g}=X_{m} \cdot I_{m}=\left(\omega_{s} L_{m}\right) \cdot I_{m} .
$$

This resistance can be calculated practically as a function of air-gap voltage when the supply voltage varies from $125 \%$ of rated value down to $25 \%$ of rated value, and by using the curve fitting technique, the relation of $R_{\mathrm{ic}(T)}-V_{g}$ can be found as a polynomial function.

Figure 2 shows the practical results of air-gap voltage variation with an iron core and mechanical resistances for the induction motor used in this work.

\section{Magnetic Saturation Effect in Iron Core Losses}

Most of the induction machines operate in the saturation region, and their magnetization characteristics are nonlinear in nature. The stator and rotor magnetizing currents and magnetizing inductance $\left(L_{m}\right)$ cannot be considered constant. The variation of magnetizing inductance is the main factor in generating an air-gap voltage $\left(V_{g}\right)$. The air-gap voltage (magnetizing voltage) can be calculated from equation (30) above.

The air-gap voltage is the main factor in generating iron core losses, according to equation (12). The magnetic satura- tion reduces the magnetizing inductance, and this, in turn, reduces the air-gap voltage and tends to increase the magnetizing current, and hence, the eddy current loss increases with saturation, and this causes increasing of iron core losses.

The saturation effect can be taken into account by using variable magnetizing inductance with the magnetizing current. The relation of magnetizing inductance as a function of magnetizing current can be obtained experimentally from the no-load machine test and the curve fitting technique. Figure 3 gives the relation of magnetizing inductance with magnetizing current, which can be represented by a fifthorder polynomial curve.

\section{Results and Discussion}

The proposed equivalent circuit of Figure 1 is simulated in the Matlab/Simulink model of induction machine used as an induction motor to calculate the iron core loss accurately at no load and at full load to show the effect of temperature, skin, and saturation on the motor core loss and hence on the motor efficiency. The simulation results are compared with practical results to show the accuracy of loss calculation. The experimental setup, as shown in Figure 4, consists of an induction machine used as a motor coupled with a DC machine used as a generator. All the specifications and parameters of these machines are given as follows:

The test setup bench consists of an induction machine coupled with a DC machine to determine the output load power of the induction machine when operates as a motor, and the DC machine is used as a generator when the machine operates as an induction motor. The specifications and parameters of the DC generator and induction motor are given as follows:

$D C$ machine: separately excited, $2.2 \mathrm{KW}, 1500$ r.p.m, $V_{\text {field }}=220 \mathrm{~V}, I_{\text {field }}=0.8 \mathrm{~A}, I_{a}=12 \mathrm{~A}, J=0.02 \mathrm{~kg} \cdot \mathrm{m}^{2}$. 


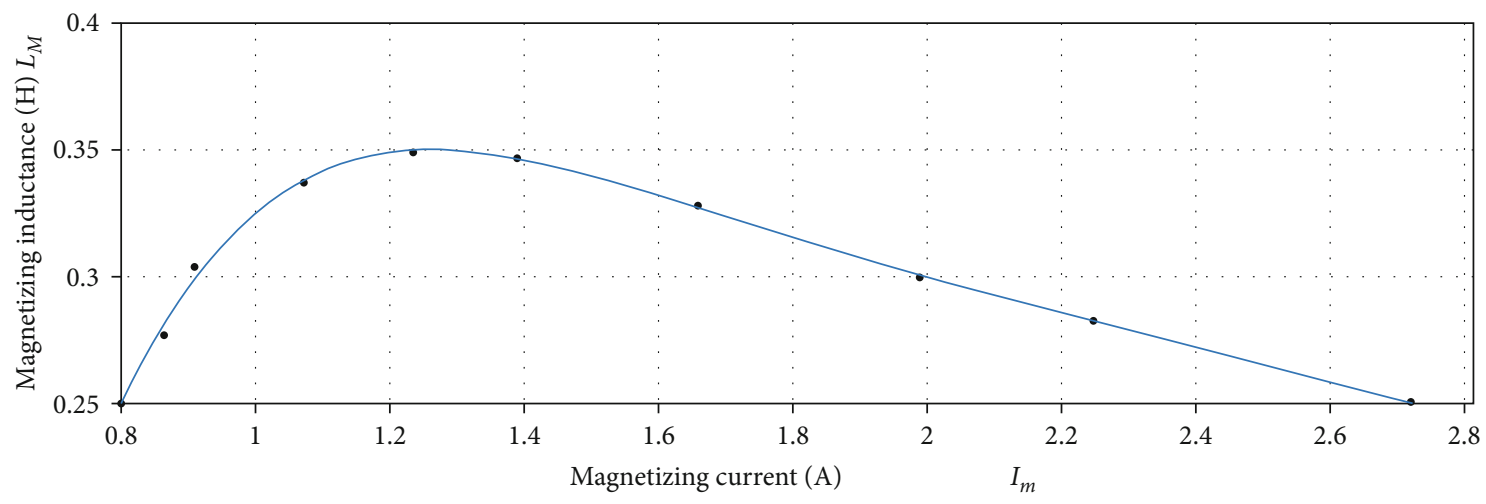

- $L_{M}$ vs. $I_{m}$

$-L_{M}=0.04765 *\left(I_{m}\right)^{\wedge} 5-0.5129 *\left(I_{m}\right)^{\wedge} 4+2.181 *\left(I_{m}\right)^{\wedge} 3-4.571 *\left(I_{m}\right)^{\wedge} 2+4.636 *\left(I_{m}\right)+0.25$

FIGURE 3: Variation of magnetizing inductance with the magnetizing current of the induction machine.

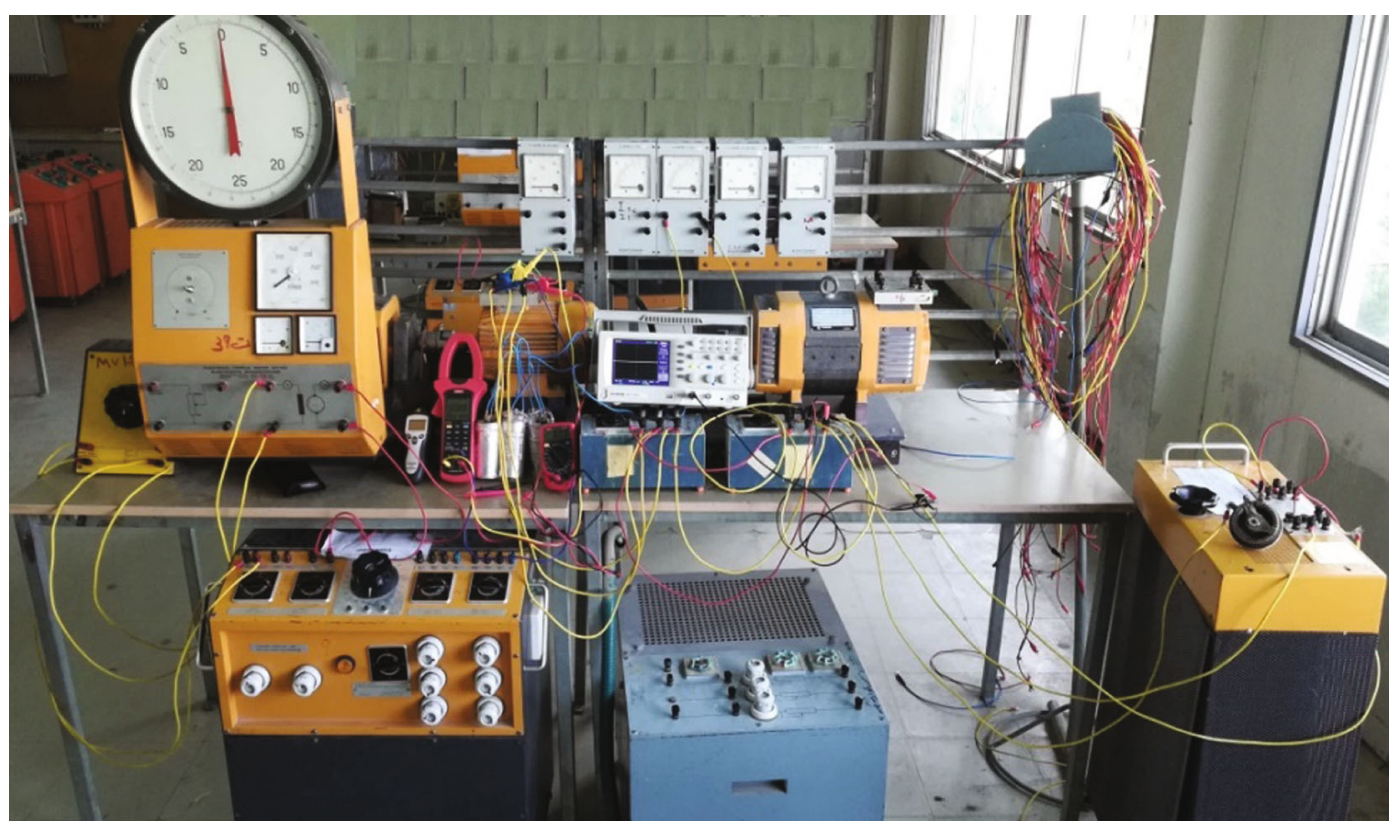

FIgURE 4: The experimental setup.

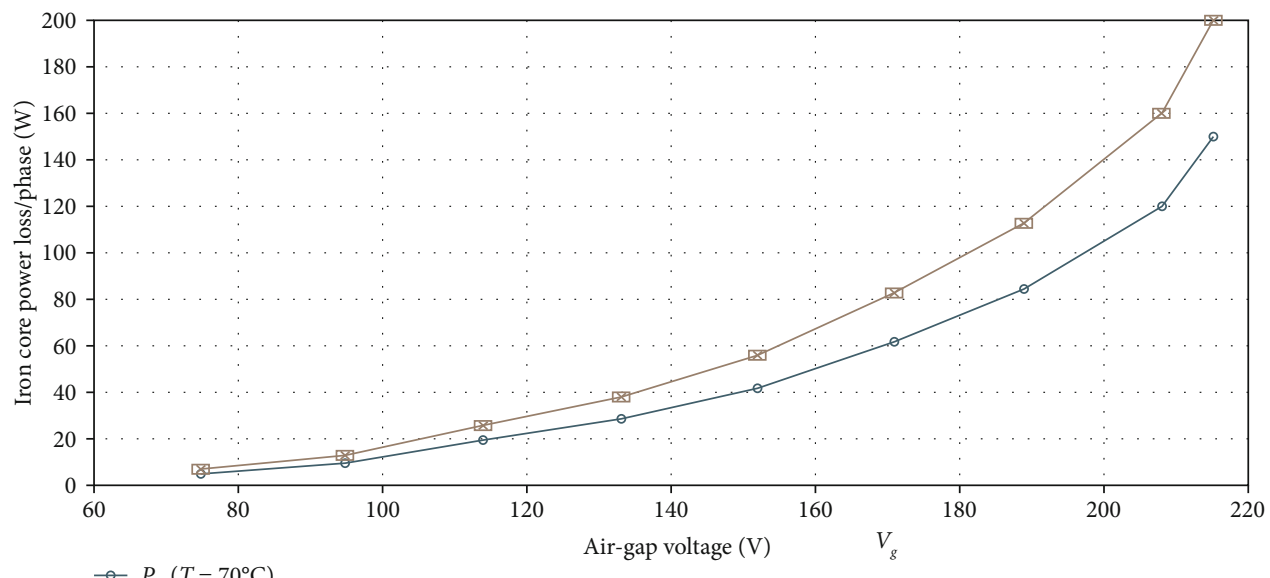

四- $P_{\text {ic }}\left(T_{0}=25^{\circ} \mathrm{C}\right)$

FIgURE 5: Variation of air-gap voltage with iron core power loss with and without temperature effect. 


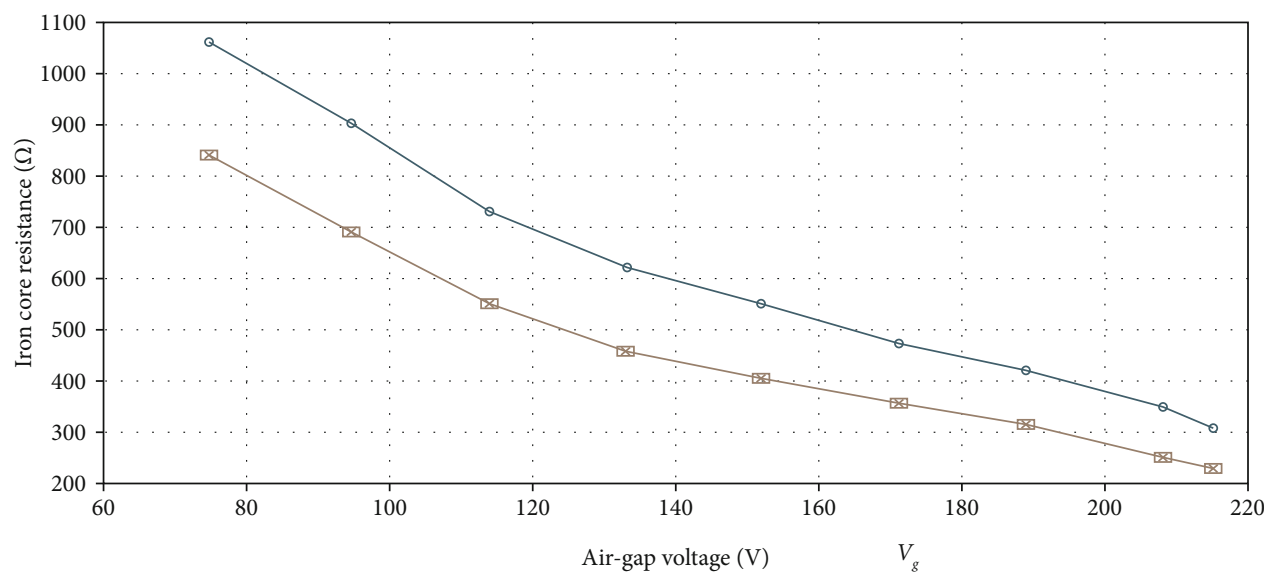

$\rightarrow R_{\mathrm{ic}}\left(T=70^{\circ} \mathrm{C}\right)$

世 $R_{\mathrm{ic}}\left(T_{o}=25^{\circ} \mathrm{C}\right)$

FIGURE 6: Variation of air-gap voltage with iron core resistance with and without temperature effect.

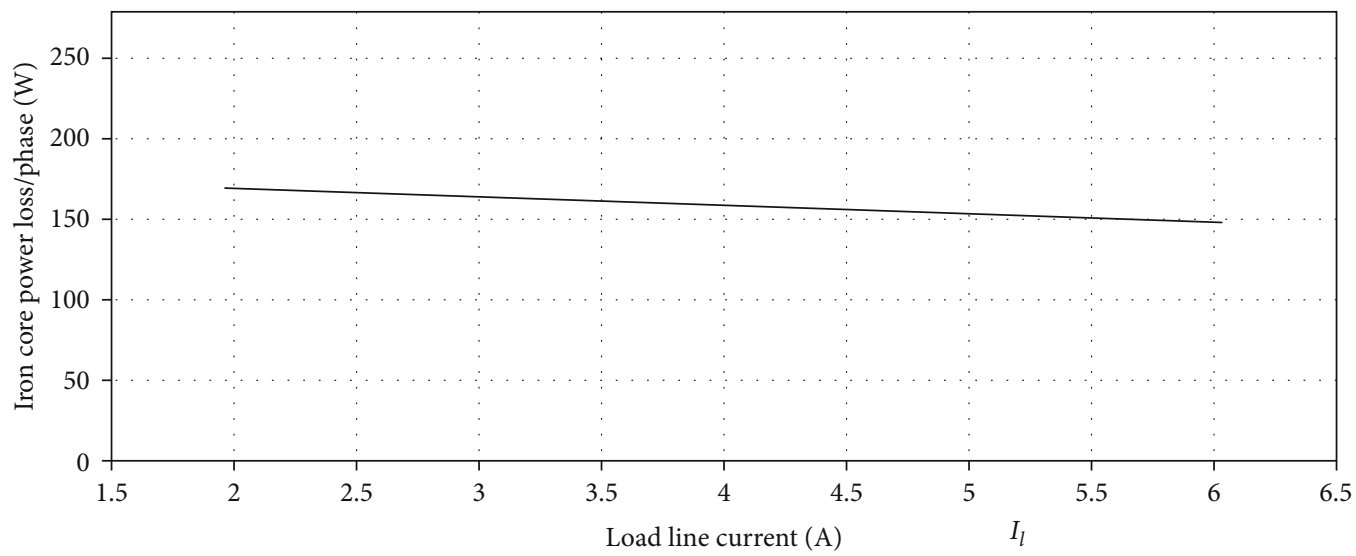

FIGURE 7: Variation of load current with iron core power loss.

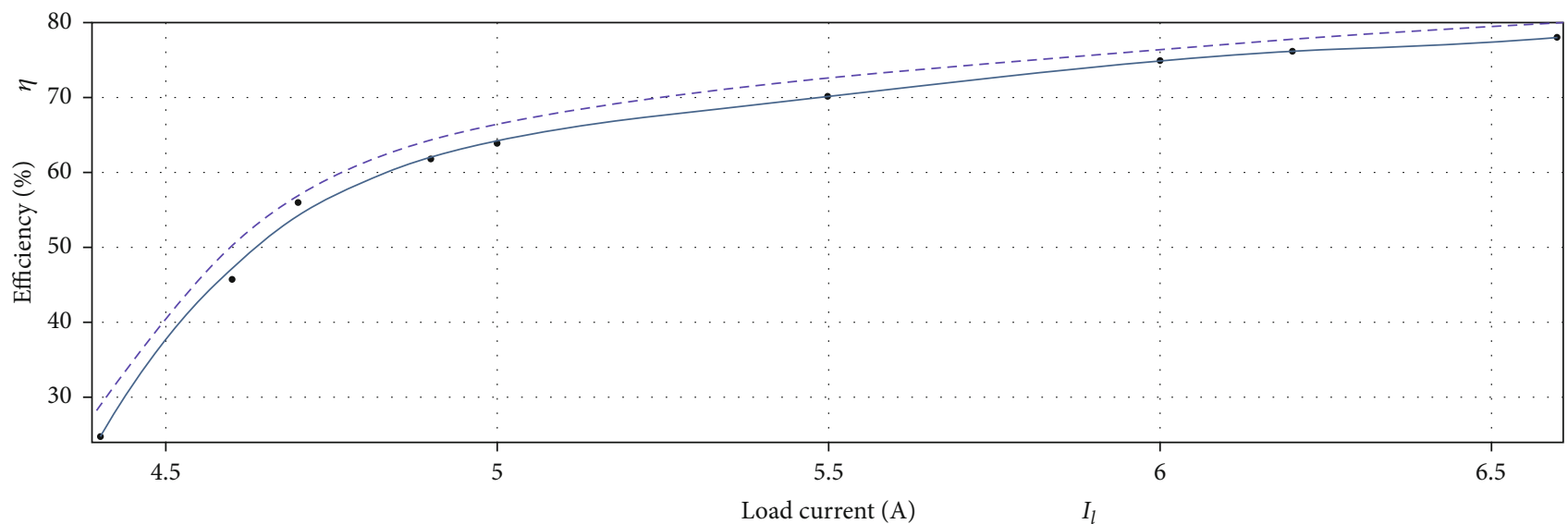

- - - Without temperature effect

— With temperature effect

FIGURE 8: Variation of load current with machine efficiency with and without temperature, skin, and saturation effect. 
Induction machine: 3 -phase, squirrel cage, $\Delta$-connected, $220 \mathrm{~V}, 50 \mathrm{~Hz}$ with the following parameters:

$P_{\text {out }}=1500 \mathrm{~W}, I_{\ell}=6.6 \mathrm{~A}, \quad \cos \phi=0.8, N_{s}=1500$ r.p.m, pair-poles $=2, \quad R_{s}=5.1 \Omega, \quad R_{r}=3.5 \Omega, \quad L_{\ell s}=0.016 \mathrm{H}$, $\dot{L}_{\ell r}=0.024 \mathrm{H}, L_{m}=0.28 \mathrm{H}, J=0.03 \mathrm{~kg} \cdot \mathrm{m}^{2}, K_{T}=0.75$.

Figures 5 and 6 show the variation of iron core power loss and iron core resistance with air-gap magnetizing voltage with and without temperature effect. Figure 7 shows the variation of iron core power loss with the load current. Figure 8 shows the variation of machine efficiency with the load current with and without temperature, skin, and saturation effect. From this figure, there is very close agreement between the calculated and measured machine efficiency at rated load current $(6 \mathrm{~A})$. When the temperature, skin, and saturation factors are neglected, large errors occur between the experimental and theoretical calculations, and this model proves the validity of introducing these factors in the calculation procedure.

\section{Conclusion}

An accurate iron core loss calculation procedure is used in the equivalent circuit model of the induction machine to improve the performance calculations of the machine. The effect of iron core temperature variation on the iron core loss is a very important factor in the calculation procedure. Also, the effect of skin and magnetic saturation is introduced in the proposed model. The iron core loss calculation is represented by iron core resistance as a part of equivalent circuit components. This resistance is used to calculate the extra or stray loss as well as iron core loss of the machine.

\section{Data Availability}

The data used to support the findings of this study are available from the corresponding author upon request.

\section{Conflicts of Interest}

The author declares no conflicts of interest in regard to this publication.

\section{References}

[1] P. L. Alger, Induction Machines: Their Behavior and Uses, Gordon and Breach Publishers, 2nd edition, 1975.

[2] G. A. McCoy, T. Litman, and J. G. Douglass, Energy-Efficient Electric Motor Selection Handbook, Washington State Energy Office, Olympia, WA, USA, 1993.

[3] A. Jalilian, Calorimetric measurement of induction motor harmonic losses, [Ph.D. thesis], University of Wollongong, Australia, 1997.

[4] E. Levi, "Impact of iron loss on behavior of vector controlled induction machines," IEEE Transactions on Industry Applications, vol. 31, no. 6, pp. 1287-1296, 1995.

[5] D. M. Ionel, M. Popescu, S. J. Dellinger, T. J. E. Miller, R. J. Heideman, and M. I. McGilp, "On the variation with flux and frequency of the core loss coefficients in electrical machines," IEEE Transactions on Industry Applications, vol. 42, no. 3, pp. 658-667, 2006.

[6] M. Popescu and D. M. Ionel, “A best-fit model of power losses in cold rolled-motor lamination steel operating in a wide range of frequency and magnetization," IEEE Transactions on Magnetics, vol. 43, no. 4, pp. 1753-1756, 2007.

[7] O. Laldin, Including frequency-dependent iron losses in analytical models of induction machines, [M.S. thesis], Helsinki University of Technology, Espoo, Finland, 2008.

[8] M. J. Manyage, Application of improved core loss formulations to machine design, [Ph.D. thesis], University of Cape Town, 2008.

[9] J. C. Akiror, Model for core loss prediction at high frequency and high flux density, [M.S. thesis], University of Concordia, Montreal, Quebec, Canada, 2012.

[10] IEEE Power Engineering Society, IEEE Standard Test Procedure for Polyphase Induction Motors and Generators, ANSI, IEEE Std 112-B, 2004.

[11] A. Boglietli, A. Cavagnino, M. Lazzari, and A. Pastorelli, "Induction motor efficiency measurements in accordance with IEEE 112-B, IEC 34-2 and JEC 37 international standards," in IEEE International Electric Machines and Drives Conference, 2003. IEMDC'03, pp. 1599-1605, Madison, WI, USA, 2003.

[12] A. Boglietti, A. Cavagnino, M. Lazzari, and M. Pastorelli, "Predicting iron losses in soft magnetic materials with arbitrary voltage supply: an engineering approach," IEEE Transactions on Magnetics, vol. 39, no. 2, pp. 981-989, 2003.

[13] M. Popescu, D. M. Ionel, A. Boglietti, A. Cavagnino, C. Cossar, and M. I. McGilp, "A general model for estimating the laminated steel losses under PWM voltage supply," IEEE Transactions on Industry Applications, vol. 46, no. 4, pp. 1389-1396, 2010.

[14] A. Bousbaine, "A thermometric approach to the determination of iron losses in single-phase induction motors," IEEE Transactions on Energy Conversion, vol. 14, no. 3, pp. 277-283, 1999.

[15] M. Ranta, M. Hinkkanen, E. Dlala, A.-K. Repo, and J. Luomi, "Inclusion of hysteresis and eddy current losses in dynamic induction machine models," in 2009 IEEE International Electric Machines and Drives Conference, pp. 1387-1392, Miami, FL, USA, 1999.

[16] G. Bertotti, "Physical interpretation of eddy current losses in ferromagnetic materials. I. Theoretical considerations," Journal of Applied Physics, vol. 57, no. 6, pp. 2110-2117, 1985.

[17] M. Basic, D. Vukadinovic, and M. Polic, "Stray load and iron losses in small induction machines under variable operating frequency and flux: a simple estimation method," IEEE Transactions on Energy Conversion, vol. 33, no. 2, pp. 869-876, 2018.

[18] J. Gyselinck, L. Vandevelde, J. Melkebeek, P. Dular, F. Henrotte, and W. Legros, "Calculation of eddy currents and associated losses in electrical steel laminations," IEEE Transactions on Magnetics, vol. 35, no. 3, pp. 1191-1194, 1999.

[19] J. Chen, D. Wang, S. Cheng, Y. Wang, Y. Zhu, and Q. Liu, "Modeling of temperature effects on magnetic property of nonoriented silicon steel lamination," IEEE Transactions on Magnetics, vol. 51, no. 11, pp. 1-4, 2015.

[20] S. Xue, W. Q. Chu, Z. Q. Zhu, J. Peng, S. Guo, and J. Feng, "Iron loss calculation considering temperature influence in non-oriented steel laminations," IET Science, Measurement \& Technology, vol. 10, no. 8, pp. 846-854, 2016. 
[21] K. Foster, "Temperature dependence of loss separation measurements for oriented silicon steels," IEEE Transactions on Magnetics, vol. 22, no. 1, pp. 49-53, 1986.

[22] N. Takahashi, M. Morishita, D. Miyagi, and M. Nakano, "Comparison of magnetic properties of magnetic materials at high temperature," IEEE Transactions on Magnetics, vol. 47, no. 10, pp. 4352-4355, 2011.

[23] S. Xue, J. Feng, S. Guo, J. Peng, W. Q. Chu, and Z. Q. Zhu, “A new iron loss model for temperature dependencies of hysteresis and eddy current losses in electrical machines," IEEE Transactions on Magnetics, vol. 54, no. 1, pp. 1-10, 2018. 